This is the peer reviewed version of the following article:

Turrini, E., Laurita, R., Simoncelli, E., Stancampiano, A., Catanzaro, E., Calcabrini, C., Carulli, G., Rousseau, M., Gherardi, M., Maffei, F., Cocchi, V., Lenzi, M., Pellicioni, V., Hrelia, P., Colombo, V., \& Fimognari, C. (2020). Plasma-activated medium as an innovative anticancer strategy: Insight into its cellular and molecular impact on in vitro leukemia cells. Plasma Processes and Polymers, 17(10), 2000007

which has been published in final form at https://doi.org/10.1002/ppap.202000007.

This article may be used for non-commercial purposes in accordance with Wiley Terms and Conditions for Use of Self-Archived Versions. 


\title{
Plasma activated medium as an innovative anticancer strategy: insight into its cellular and molecular impact on in vitro leukemia cells.
}

Eleonora Turrini ${ }^{1}$, Romolo Laurita ${ }^{2,3,{ }^{*}, \#}$, Emanuele Simoncelli ${ }^{2, \#}$, Augusto Stancampiano ${ }^{2,4}$, Elena Catanzaro $^{1}$, Cinzia Calcabrini ${ }^{1}$, Giovanni Carulli ${ }^{5}$, Martina Rousseau ${ }^{5}$, Matteo Gherardi ${ }^{2,3}$, Francesca Maffei ${ }^{1}$, Veronica Cocchi ${ }^{6}$, Monia Lenzi ${ }^{6}$, Valentina Pellicioni ${ }^{1}$, Patrizia Hrelia ${ }^{6}$, Vittorio Colombo $^{2,3}$, Carmela Fimognari ${ }^{1, *}$

${ }^{1}$ Department for Life Quality Studies, Alma Mater Studiorum - Università di Bologna, Rimini, Italy: eleonora.turrini@unibo.it; elena.catanzaro2@unibo.it; cinzia.calcabrini@unibo.it; francesca.maffei@unibo.it; valentina.pellicioni@studio.unibo.it; carmela.fimognari@unibo.it

${ }^{2}$ Department of Industrial Engineering, Alma Mater Studiorum - Università di Bologna, Bologna, Italy: romolo.laurita@unibo.it; emanuele.simoncelli@unibo.it; augusto.stancampiano@unibo.it; matteo.gherardi4@unibo.it; vittorio.colombo@unibo.it

${ }^{3}$ Industrial Research Center for Advanced Mechanical and Materials, Alma Mater Studiorum Università di Bologna, Bologna, Italy: romolo.laurita@unibo.it; matteo.gherardi4@unibo.it; vittorio.colombo@unibo.it

${ }^{4}$ Presently at GREMI, UMR7344 CNRS/Université d'Orléans, Orléans, France

${ }^{5}$ Division of Hematology, Department of Clinical and Experimental Medicine, Università di Pisa, Pisa, Italy: g.carulli@ao-pisa.toscana.it; martina.rousseau@live.it

${ }^{6}$ Department of Pharmacy and Biotechnology, Alma Mater Studiorum - Università di Bologna, Bologna, Italy: veronica.cocchi4@unibo.it; m.lenzi@unibo.it; patrizia.hrelia@unibo.it

\# These authors contributed equally to this article.

* Correspondence: romolo.laurita@unibo.it (R.L.); carmela.fimognari@unibo.it (C.F.)

\begin{abstract}
Cold atmospheric plasma (CAP) has gained interest as potential anticancer strategy. In this work, culture medium was exposed to a microsecond pulsed dielectric-barrier-discharge jet in order to produce plasma activated medium (PAM). On T-lymphoblastic cell line, PAM induced apoptosis through the activation of the intrinsic pathway and inhibited cell-cycle progression. The use of the scavengers NAC or O-phenantroline significantly decreased PAM pro-apoptotic activity. The genetic impact of PAM was assessed on TK6 cells, resulting in increased micronuclei frequency. PAM showed cytotoxic effects even on leukemia cells cultivated in hypoxia, which plays a critical role in promoting chemoresistance. PAM was also tested on normal lymphocytes, showing its partial selectivity. Taken together, these results contribute to understand the pharmaco-toxicological profile of CAP.
\end{abstract}

\section{Introduction}

Plasma is the fourth state of matter, a globally-neutral ionized gas composed of ions, electrons, and neutral reactive species. Cold atmospheric plasma (CAP) is a specific type of plasma generated 
at atmospheric pressure characterized by a macroscopic temperature lower than $40^{\circ} \mathrm{C}$, allowing its use for biomedical applications.[1] As a matter of fact, CAP technology is a relative newcomer to the field of medicine. Very recent exponential developments in electronics and pulsed power engineering have promoted consequent significant improvements in the design of CAP-based sources and devices for medical purposes. [2] In recent years, the main biomedical applications of CAP were: wound healing, blood coagulation, antibacterial treatment, induction of cancer cells death, and stimulation of endothelial cell proliferation.[3] The biological effects of CAP result from the interaction of its physical and chemical components with cells. Ultraviolet radiation, heat and electromagnetic field represent the physical factors. The chemical ones are mainly represented by the reactive oxygen and nitrogen species (RONS) [e.g. hydroxyl radical $(\mathrm{OH})$, singlet oxygen $\left({ }^{1} \mathrm{O}_{2}\right)$, superoxide anion $\left(\mathrm{O}_{2} \cdot{ }^{-}\right)$, hydrogen peroxide $\left(\mathrm{H}_{2} \mathrm{O}_{2}\right)$, hypochlorite $\left(\mathrm{OCl}^{-}\right)$, ozone $\left(\mathrm{O}_{3}\right)$, nitric oxide (NO), nitrogen dioxide $\left(\mathrm{NO}_{2}\right)$, nitrogen trioxide $\left(\mathrm{NO}_{3}\right)$, nitrous oxide $\left(\mathrm{N}_{2} \mathrm{O}\right)$, dinitrogen tetroxide $\left(\mathrm{N}_{2} \mathrm{O}_{4}\right)$, nitrites $\left(\mathrm{NO}_{2}{ }^{-}\right)$and peroxynitrite $\left.\left(\mathrm{ONOO}^{-}\right)\right]$, [4] which are the key mediators of oxidative damage and cell death in biological systems. [5] In fact, RONS are responsible for cell membrane alterations, increase in intracellular ROS, decrease in the antioxidant potential, induction of DNA double-strand breaks, and apoptosis. Over the past few decades, CAP has been proposed as an innovative anticancer strategy.[6] So far, a rapidly growing body of evidence was produced on its antitumor ability in in vitro and murine models over a wide range of cancers, i.e. melanoma, lung, ovarian, colon, prostate cancers, and haematological malignancies.[7-9] The mechanisms of CAP anticancer activity include the modulation of many cellular pathways, such as PI3K/AKT, Ras/MAPK, ATM/p53, and TNF/ASK1, as demonstrated in different cancer cell lines.[10] Non the less, CAP activates tumor-reactive adaptative immune responses that represent a critical requirement for in vivo, thus, clinical effectiveness [11,12]. Furthermore, it was recently shown that CAP induces apoptosis on colon and lung cancer cells via endoplasmic reticulum stress.[13] Besides, CAP is able to elicit cell death through alternative non-apoptotic mechanisms, such as autophagy and possibly ferroptosis, a type of programmed cell death dependent on iron and characterized by the accumulation of lipid peroxides. [14] Moreover, CAP can stimulate macrophages and induce immunogenic cell death, [15] a special type of apoptosis able to convert dying or dead cancer cells into a "vaccine", thus inducing an anticancer immunity.[16]

CAP can affect cancer cells' growth and viability both through a direct or an indirect exposure. In the first case, there is the direct contact of cells with plasma; in the second one, cells are treated with plasma activated media/liquids (PAM/PALs).[17,18] However, only preliminary results are available on the clinical application of CAP in the oncologic field.[19] Among the devices used for the generation of CAP, plasma jet is actually the most employed discharge device.[20]

Through an integrated experimental approach, in the present study, we explore the anticancer effects of PAM produced exposing RPMI to a dielectric barrier discharge (DBD) plasma jet. To this end, we investigated in vitro the cellular and genetic impact of PAM in lymphoblastic leukemia cells. In particular, we explored necrotic/apoptotic events, cell-cycle progression, and induction of DNA damage after PAM exposure. Moreover, we studied the selectivity of PAM for tumour cells through the analysis of its cytotoxic effects on T-lymphocytes from healthy donors that do not exhibit the malignant properties of leukemic cells, representing their non-transformed, normal counterpart. Hematological tumor cell lines have been used for decades in the oncological field for their easy cultivability and simple execution of many analyses by flow cytometry, which is the current gold standard for analyses such as cell proliferation and cell death mechanisms.

Hematological tumor cell lines can also allow a specific comparison between the plasma effects on malignant ( T-leukemia cells and normal T lymphocytes) cells. This is essential to determine the 
plasma selectivity. Moreover, the experimental approach also allows evaluating the effect of plasma on blasts from leukemia patients, where we investigated the cytotoxicity of PAM. This is an aspect of particular importance, hardly feasible for solid tumors, for which the obtaining of ex vivo material requires the availability of biopsy specimens of difficult availability and cultivability. Ex vivo samples represent a quite good surrogate for determining the cellular response of the patient to the treatment and predicting the clinical outcome.[21] With the aim to preliminary predict the clinical potential of PAM and aware of the consequences of oxygen levels for RONS production, [22]we tested its cytotoxic effects in hypoxic conditions, a model of chemoresistance. Hypoxia characterizes not only solid tumors, but also leukemia. Bone marrow hematopoietic compartment has an oxygen gradient ranging from $<6 \%$ oxygen to anoxia. $[23,24]$ In solid cancers, uncontrolled proliferation is associated with hypoxia, which has been found to favor chemoresistance.[25-27] The rapidity of blast cell proliferation would eventually reduce the oxygen availability. Accordingly, in a rat model of promyelocytic leukemia, Jensen et al. [28] observed an increasing level of hypoxia during disease progression, comparable to that observed in solid tumors.

For the first time, we demonstrated the cytotoxic potential of PAM in hypoxia and its partial selectivity for malignant cells.

\section{Materials and Methods}

\subsection{CAP source}

The CAP device used for the experiments was a DBD plasma jet source.[29] As high-voltage electrode, a $50 \mathrm{~mm}$ long tungsten wire having $1 \mathrm{~mm}$ diameter was used; the wire was positioned on the axis of a borosilicate glass capillary having a dielectric constant $\varepsilon_{\mathrm{r}} \sim 5$. As grounded electrode, a $40 \mathrm{~mm}$ width aluminium foil was wrapped outside the dielectric capillary. In order to make the source suitable for biomedical applications, plasma propagates inside the capillary, $150 \mathrm{~mm}$ long, decoupling the area of plasma generation from the area dedicated to the treatment. The borosilicate glass capillary ended with a $25 \mathrm{~mm}$ long section characterized by an inclination of $75^{\circ}$ and a tapered orifice. As working gas, 3 standard liters per minute (slpm) of $99.999 \%$ pure helium (He) was introduced for sustaining and propagating CAP. CAP plume was produced downstream the spruce orifice, where the mixing of He plasma with the surrounding air occurred.

The source is driven by a micropulsed high voltage generator (PVM 500/DIDRIVE10, Information Unlimited, US). The waveform characteristic is a $22 \mathrm{kHz}$ sinusoid with peak voltage that could be varied in the range $7-18 \mathrm{kV}$. The generator was operated imposing a $7.5 \%$ duty cycle ( $0.75 \mathrm{~ms}$ ON, $9.25 \mathrm{~ms}$ OFF).Voltage and current were monitored by means of high voltage probe (Tektronix P6015A) connected to an oscilloscope (Tektronix DPO 40034). The distance between the source outlet and the liquid to be treated was fixed at $11 \mathrm{~mm}$.

\subsection{Cell cultures}

We used authenticated human T-leukemia cells (Jurkat) (LGC Standard, Teddington, Middlesex, UK) and spleen lymphoblast cell line (TK6) (Sigma Aldrich, St. Louis, Missouri, USA), grown in suspension and propagated in RPMI 1640 added with 10\% inactivated fetal bovine serum (FBS), 1\% L-glutamine (L-glu) $200 \mathrm{mM}$, and 1\% penicillin/streptomycin solution (all purchased by Sigma). To maintain exponential growth, cells were cultured at $37^{\circ} \mathrm{C}$ and $5 \% \mathrm{CO}_{2}$ and divided every three days to a concentration of $1 \times 10^{5}$ and $2 \times 10^{5}$ cells $/ \mathrm{mL}$, respectively. 
To assess selectivity, we used lymphocytes isolated from peripheral blood of healthy donors, provided by AVIS (Association of Voluntary Italian Blood Donors). All donors provided written informed consent. Lymphocytes were isolated by centrifugation on Ficoll-Histopaque density gradient. Mononuclear cells at interphase (cell-cycle phase for mitosis preparation) were recovered, washed with PBS 1x solution and then suspended in RPMI 1640 added with 15\% FBS, 1\% L-glu, $1 \%$ antibiotics solution and $0.5 \%$ phytohemagglutinin $(2 \mathrm{mg} / \mathrm{mL}$, Sigma).

\subsection{Treatment conditions}

PAM was produced exposing $1 \mathrm{ml}$ of serum-free RPMI to CAP (Figure 1). After PAM production, we seeded malignant or normal cells in this activated medium. To standardize the procedure of indirect treatment and to avoid any variables related to the kinetics of RONS in liquid phase, a delay time of 30 seconds between PAM production and cell treatment was fixed. Tested operating conditions were $10 \mathrm{kV}$ with a treatment time of 120 or $180 \mathrm{~s} .1$ or $3 \mathrm{~h}$ after PAM treatment, the activated medium was replaced with complete medium. Furthermore, some experiments were performed in presence of N-acetylcysteine (NAC, $10 \mathrm{mM}$, Sigma) or Ophenantroline (O-phe, 1-100 $\mu \mathrm{M}$, Sigma).
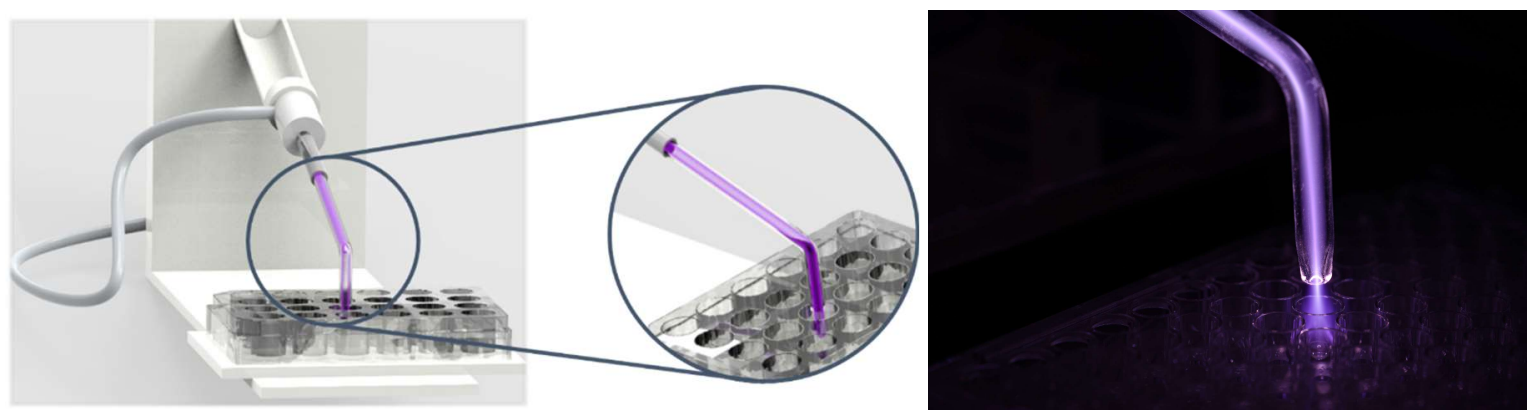

Figure 1. Schematic (left) and picture (right) of the experimental setup for the production of PAM

To explore the role of ROS in the cytotoxic activity of PAM, leukemic cells were additionally cultivated in a hypoxia workstation (INVIVO 200, Ruskinn Technology Ldt, Bridgend, $\mathrm{UK}$ ), at $\mathrm{O}_{2}$ concentration up to $1 \%$. PAM production, cell treatments, and sample preparations were performed inside the workstation, ensuring full maintenance of hypoxic condition for the entire duration of the experiments.

\subsection{Flow cytometry}

All flow cytometric analyses were performed by the EasyCyte 5HT flow cytometer (Merck Darmstadt, Germany) or Guava EasyCyte 6-2L (Merck, Darmstadt, Germany). At least 5000 events were evaluated for each analysed sample.

\subsection{Analysis of cell viability}

24 or $48 \mathrm{~h}$ from $1 \mathrm{~h}-\mathrm{PAM}$ exposure, Jurkat cells or lymphocytes were stained with Guava Viacount reagent (Merck, Darmstadt, Germany), containing 7-amino-actinomycin D (7-AAD), that allows the discrimination between viable and dead cells, and incubated at room temperature in the dark for $5 \mathrm{~min}$ before flow-cytometric analysis. To discriminate between necrotic and apoptotic events, we used Guava Nexin reagent (Merck), containing 7-AAD and ANNEXIN-Vphycoerythrin. Briefly, $2 \times 10^{4}$ cells were stained with $100 \mu \mathrm{L}$ of Guava Nexin reagent and, after 20 
min incubation at room temperature in the dark, samples were analysed via flow cytometry. Camptothecin $2 \mu \mathrm{M}$ (Sigma) was used as positive control.

\subsection{Cell-cycle analysis}

Guava Cell Cycle Reagent (Merck), containing propidium iodide, was used to identify cells in the different phases of cell cycle, based on DNA content. After $24 \mathrm{~h}$ from $1 \mathrm{~h}$-PAM treatment, cells were fixed with ice-cold ethanol 70\%. After fixation, cells were washed with PBS 1x, suspended in $200 \mu \mathrm{L}$ of reagent, incubated for $30 \mathrm{~min}$ at room temperature and protected from light and finally analysed via flow cytometry. Etoposide $0.2 \mu \mathrm{M}$ (Sigma) was used as positive control.

\subsection{Analysis of mitochondrial transmembrane potential}

The involvement of the apoptotic mitochondrial pathway was assessed through MitoProbe ${ }^{\mathrm{TM}}$ DilC1(5) Assay kit (Thermo Fisher Scientific, Walthman, MA, USA). After $24 \mathrm{~h}$ from $1 \mathrm{~h}-\mathrm{PAM}$ exposure, Jurkat cells were washed and supplemented with $50 \mathrm{nM} \operatorname{DilC1}(5)$ (1,10,3,3,30,30hexamethylindo dicarbo-cyanine iodide) for $20 \mathrm{~min}$ at $37^{\circ} \mathrm{C}$ and $5 \% \mathrm{CO}_{2}$. DilC1(5) freely accumulates in mitochondria with active membrane potential. At the end of the incubation, cells were washed and suspended again in PBS 1x for the flow-cytometric analysis. Carbonyl cyanide 3chlorophenylhydrazone (CCCP) $50 \mu \mathrm{M}$ was used as positive control. Results were expressed as \% of cells with decreased mitochondrial potential compared to untreated cells.

\subsection{Detection of intracellular glutathione (GSH) level}

Intracellular GSH represents the main antioxidant defence of cells exposed to oxidative stress (PMID: 18796312). Besides, depletion of intracellular GSH is responsible for redox imbalance and cells become more susceptible to ROS damage due to the loss of scavenging power. [30] 2,2'-Dinitro-5,5'-dithiodibenzolic acid (DTNB, Sigma) was used to measure GSH levels in Jurkat cells. Briefly, after $1 \mathrm{~h}$ of PAM treatment and $5 \mathrm{~h}$ of recovery in complete medium, samples were lysed through freezing-thawing protocol. Supernatant containing cytoplasmic proteins was collected and proteins measured by Bradford assay (Bio-Rad, Hercules, CA, USA) [31]. Then, a 50 $\mu \mathrm{L}$ sample was mixed with $100 \mu \mathrm{l}$ TRIS EDTA (pH 8,9; 0,2 M, Sigma) and $50 \mu 1$ DTNB (dissolved in methanol). $\mathrm{H}_{2} \mathrm{O}_{2}$ was used as positive control at $60 \mu \mathrm{M}$, which corresponds to the highest $\mathrm{H}_{2} \mathrm{O}_{2}$ concentration recorded in PAM in our tested experimental conditions. The spectrophotometric analysis was performed at $405 \mathrm{~nm}$ within 5 min with a microplate reader (Tecan, Männedorf. Switzerland). Results were normalized according to proteins' content of each sample. Results were expressed as \% of GSH depletion compared to untreated cells.

\subsection{H2AX phosphorylation assay and MN assay}

To investigate whether PAM was able to induce DNA damage on Jurkat cells, the phosphorylation of H2AX ( $\gamma-\mathrm{H} 2 \mathrm{AX})$ was analysed using FlowCellect ${ }^{\mathrm{TM}}$ Histone H2AX Phosphorylation Assay Kit (Merck). Briefly, $1 \mathrm{~h}$ after PAM exposure followed by 4 or $21 \mathrm{~h}$ of recovery in complete medium, cells were fixed and permeabilized, according to manufacturer's instruction. After permeabilization, cells were incubated for $30 \mathrm{~min}$ with the anti- $\gamma$-H2AX-Alexa Fluor antibody (Merck). Etoposide $10 \mu \mathrm{g} / \mathrm{mL}$ was used as positive control. Samples were analysed via flow cytometry and the results expressed as fold increase of $\gamma-\mathrm{H} 2 \mathrm{AX}$ versus untreated cells.

To assess PAM mutational effects, the micronucleus test was conducted on TK6 cells, as recommended by OECD (Organization for Economic Co-operation and Development) guidelines 487 [32]. After $3 \mathrm{~h}$ from PAM exposure followed by $21 \mathrm{~h}$ of recovery in complete fresh medium, as recommended by the OECD guidelines, aliquots of $7 \times 10^{5}$ of TK6 cells were collected and stained 
with 7-AAD and SYTOX Green. Since micronuclei (MN) are characterized by a fluorescence of about $1 / 100^{\text {th }}$ of the G1 nuclei's fluorescence intensity [33,34], we positioned the MN scoring region for SYTOX fluorescence between $10^{2}$ and $10^{3}$. For each sample, the MN frequency was measured on 10,000 nuclei derived from viable and proliferating cells on the basis of the different 7-AAD fluorescence. Positive controls were mitomycin (MMC, Sigma) $0.8 \mu \mathrm{g} / \mathrm{mL}$ and vinblastine (VINB, Sigma) $0.025 \mu \mathrm{g} / \mathrm{mL}$ for $3 \mathrm{~h}$. The results are expressed as increased frequency of $\mathrm{MN}$ in treated cultures compared to that present in the control cultures.

2.10 Detection of reactive oxygen and nitrogen species in PAM.

The concentrations of hydrogen peroxide and nitrites were assessed using the Amplex ${ }^{\circledR}$ Red Hydrogen Peroxide Assay Kit (Thermo Fisher Scientific) and the nitrate/nitrite colorimetric assay (ROCHE, Basel, Switzerland), respectively. The measurement of these reactive species was performed $30 \mathrm{~s}$ after PAM production according to the manufacturer's protocols. The absorbances were measured photometrically with a microplate reader (Rayto, Shenzhen, P.R. China).

\subsection{Statistical analysis}

Results are expressed as the mean \pm SEM of at least three independent experiments. T-test for paired data or ANOVA repeated measures was used. Bonferroni or Dunnett were used as posttests. The statistical software GraphPad InStat 5.0 version (GraphPad Prism, San Diego, CA, USA) was used. $\mathrm{P}<0.05$ was considered significant.

\section{Results}

\subsection{PAM induces apoptosis of Jurkat cells}

A significant decrease in Jurkat viability was observed at all tested conditions, characterized after $24 \mathrm{~h}$ from PAM exposure by an increase in both necrotic and apoptotic events: with PAM generated by $10 \mathrm{kV} 120 \mathrm{~s}$ we observed $19 \%$ of both necrotic and apoptotic events, compared to 2.6\% necrosis and 6.0\% apoptosis for untreated cells (Figure 2a). A significant increase in apoptotic events, rather than necrotic ones, was observed $48 \mathrm{~h}$ after treatment (Figure $2 \mathbf{b}$ ).

Moreover, $24 \mathrm{~h}$ after treatment, PAM increased the percentage of cells with reduced mitochondrial potential. The highest effect was recorded for PAM $180 \mathrm{~s}$, with $29.7 \%$ of cells with decreased mitochondrial potential (versus 2.6\% of untreated cells) (Figure 2c). 
(a)

24h

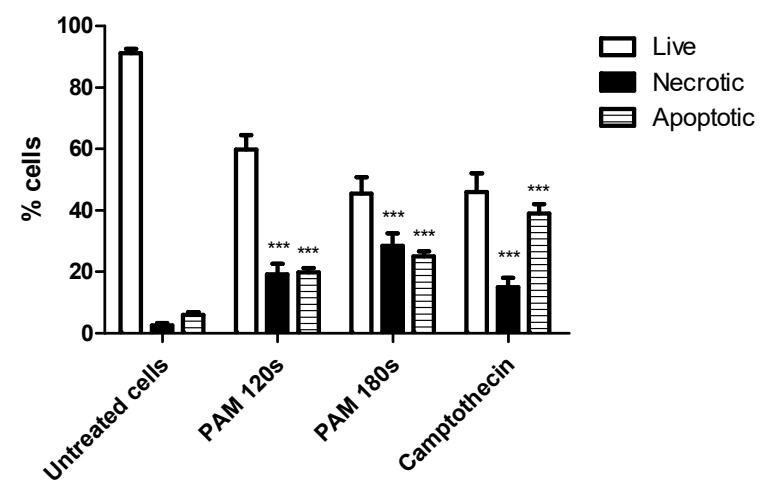

(c)

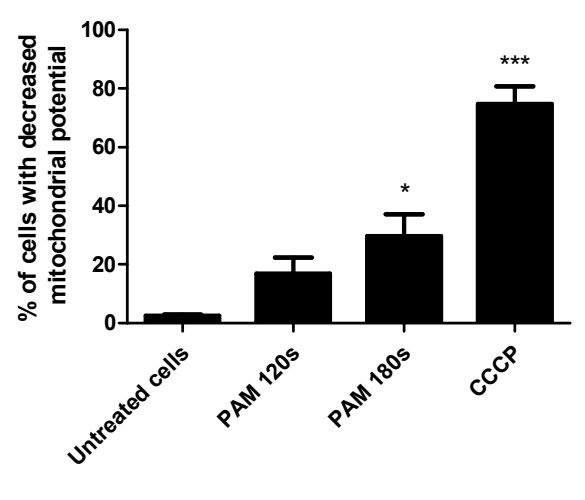

(b)

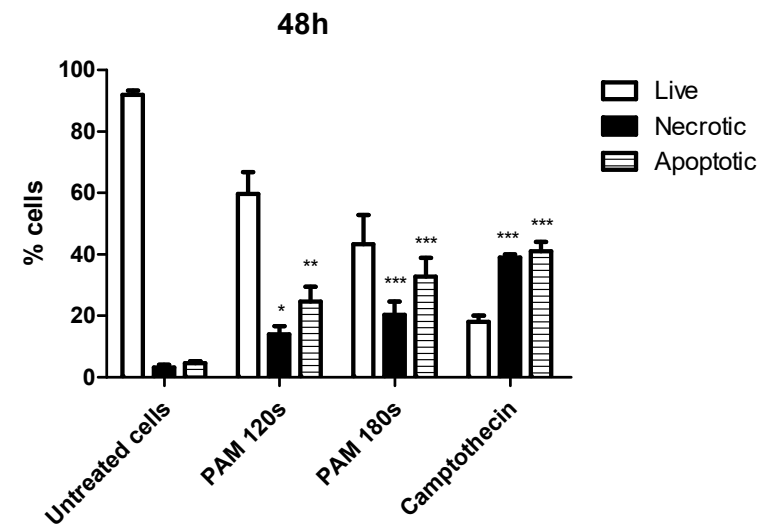

CCCP: carbonyl cyanide 3-chlorophenylhydrazone

Figure 2. Percentage of live, necrotic and apoptotic Jurkat cells after 24 (a) and $48 \mathrm{~h}$ (b) from PAM exposure. Data are the mean of six independent experiments. Camptothecin was used as positive control. (c) Percentage of cells with decreased mitochondrial potential $24 \mathrm{~h}$ after PAM exposure. Results are the mean of three independent experiments. CCCP was used as positive control. *p $<$ $0.05 ; * * \mathrm{p}<0.01 ; * * * \mathrm{p}<0.001$ versus untreated cells.

\subsection{PAM induces cell-cycle arrest of Jurkat cells}

Two are the major phases of cell cycle: interphase and mitotic phase. Interphase consists of three steps: G1, S and G2, in which a cell grows and makes a copy of its DNA in preparation of the mitosis (M phase). $24 \mathrm{~h}$ after PAM treatment, a decrease of the number of cells in the G0/G1 phase with a compensatory increase in the $\mathrm{S}$ and G2/M phases was recorded. At PAM $180 \mathrm{~s}$, we observed the highest increase in cells in G2/M (28.0\% compared to $17.8 \%$ of untreated cells) and S phase ( $23.1 \%$ compared to $16.9 \%$ of untreated cells) with a decrease in cells in the $\mathrm{G} 0 / \mathrm{G} 1$ phase $(49.5 \%$, compared to $65.6 \%$ of untreated cells) (Figure 3). 


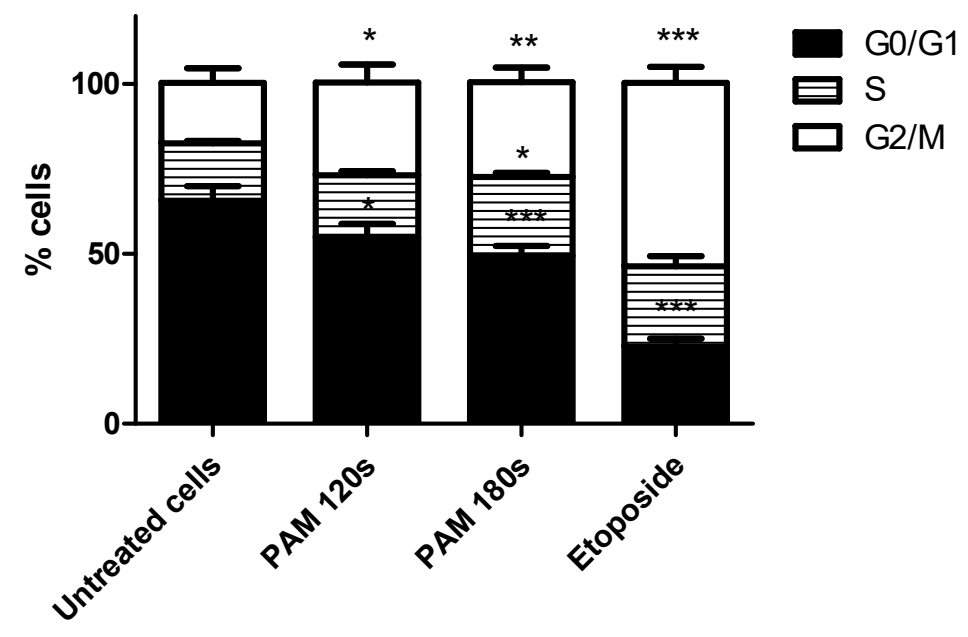

Figure 3. Cell-cycle distribution of Jurkat cells $24 \mathrm{~h}$ after PAM exposure. Results are the mean of three independent experiments. Etoposide was used as positive control. ${ }^{*} \mathrm{p}<0.05 ;{ }^{* *} \mathrm{p}<0.01 ; * * * \mathrm{p}$ $<0.001$ versus untreated cells.

\subsection{RONS are involved in the cytotoxic effects of PAM on Jurkat cells}

Due to the key role of ROS in CAP biological activity [5], we investigated how the alteration of the redox state could influence the cytotoxic activity of PAM. We performed some experiments treating the cells $1 \mathrm{~h}$ before PAM exposure with NAC, which reduces GSH oxidation, or O-phe, which blocks the Fenton reaction. After $24 \mathrm{~h}$, we observed with both scavengers a $20 \%$ of increase in cell viability, indicating the involvement of both these pathways in PAM biological activity (Figure 4a,c). For example, after PAM treatment for $120 \mathrm{~s}$, the viability was $46.9 \%$, whereas in the presence of NAC or O-phe the viability was 63.5\% and 69.3\%, respectively (Figure 4a,c). After 48 $\mathrm{h}$, we observed a similar trend; in particular, at PAM $120 \mathrm{~s}$, the viability was $66.4 \%$ in the presence of NAC and $80.5 \%$ in the presence of O-phe, compared to $52.2 \%$ after PAM exposure (Figure 4b,d).

To further proof the role of ROS in the anticancer activity of PAM, we treated cells with NAC for $20 \mathrm{~h}$ before PAM exposure and we additionally added NAC in each sample after PAM treatment, thus increasing intracellular GSH levels. The analysis of viability was performed 24 and $48 \mathrm{~h}$ later. The results clearly showed an increase in cell viability, more pronounced than that observed after only $1 \mathrm{~h}$ of NAC pre-treatment. For example, after $24 \mathrm{~h}$ at PAM $120 \mathrm{~s}$ the viability of cells exposed to PAM was $51 \%$ compared to $84 \%$ for cells treated with NAC (Figure $4 \mathbf{e}$ ). The same trend was recorded $48 \mathrm{~h}$ after PAM treatment (Figure 4f) and at PAM $180 \mathrm{~s}$ (data not shown). On the whole, our results indicate that NAC did not totally abolish PAM-induced cytotoxicity. 
(a)

$24 \mathrm{~h}$

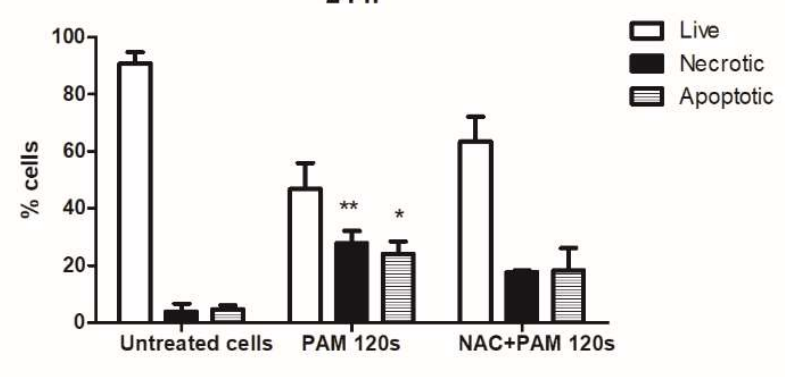

(c)

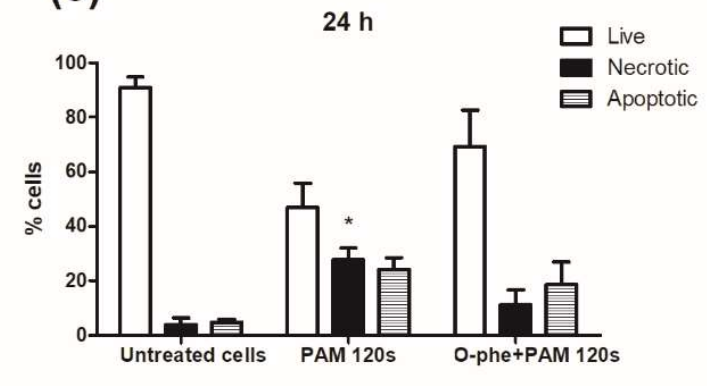

(e)

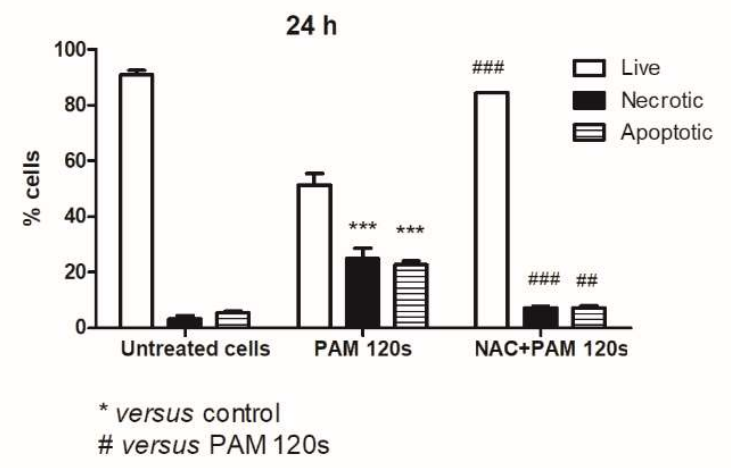

(b)

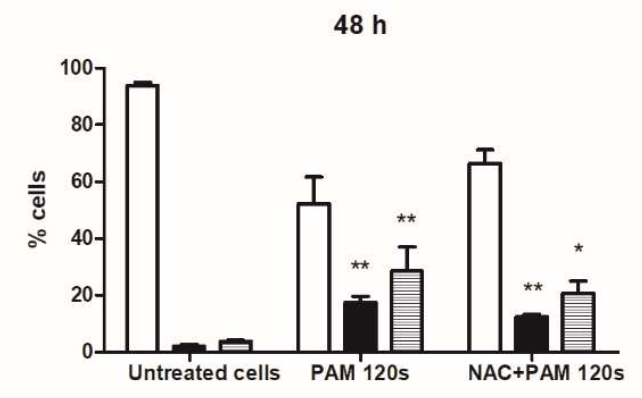

(d)

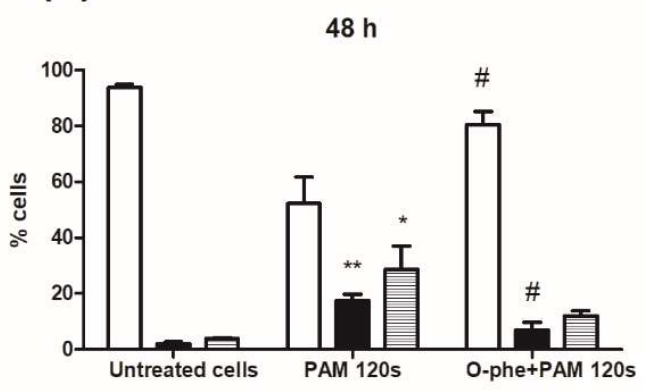

(f)

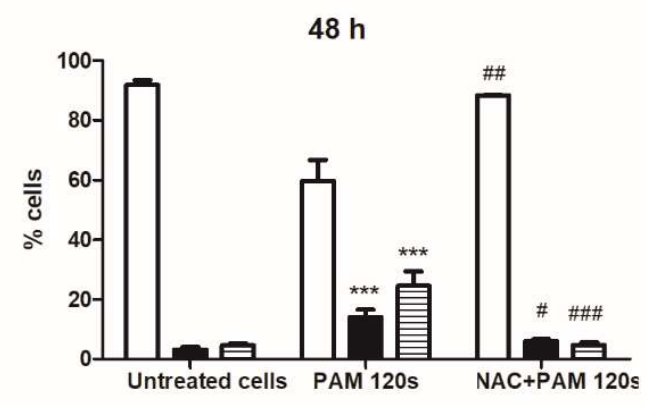

Figure 4. Percentage of live, necrotic and apoptotic Jurkat cells after 24 and $48 \mathrm{~h}$ from PAM treatment $(120 \mathrm{~s})$ in presence or absence of NAC $(\mathrm{a}, \mathrm{b})$ or O-phe $(\mathrm{c}, \mathrm{d}) 1 \mathrm{~h}$ or $20 \mathrm{~h}(\mathrm{e}, \mathrm{f})$ before PAM exposure. Results are the mean of three independent experiments. $* \mathrm{p}<0.05 ; * * \mathrm{p}<$ $0.01 ; * * * \mathrm{p}<0.001$ versus untreated cells; $\# \mathrm{p}<0.05$; \#\# $\mathrm{p}<0.01$; \#\#\# $\mathrm{p}<0.001$ versus PAM treatment condition $10 \mathrm{kV} 120 \mathrm{~s}$.

Considering the decrease in PAM-cytotoxicity in presence of NAC, we further investigated the ability of PAM to deplete GSH. Since GSH depletion is an upstream event compared to apoptosis, we measured GSH levels $6 \mathrm{~h}$ after PAM treatment [35]. We observed that PAM treatment decreased GSH intracellular levels at all tested conditions (Figure 5). 


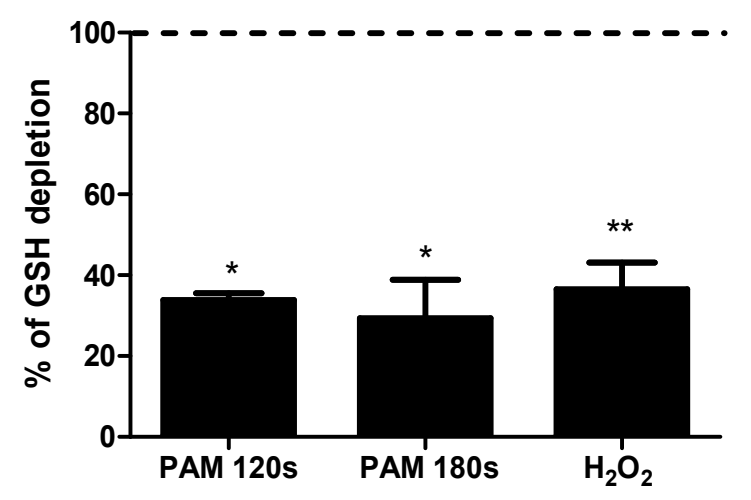

Figure 5. Percentage of intracellular GSH depletion in Jurkat cells $6 \mathrm{~h}$ after PAM exposure. Results are the mean of three independent experiments. $\mathrm{H}_{2} \mathrm{O}_{2}$ was used as positive control. $* \mathrm{p}<0.05 ;{ }^{*} \mathrm{p}<0.01$ versus untreated cells (dashed line).

\subsection{PAM induces DNA damage in Jurkat and TK6 cells}

The key role that RONS play in CAP biological activity prompt us to investigate PAM genotoxicity. We used the H2AX histone phosphorylation assay on Jurkat cells to investigate whether PAM was able to induce DNA damage. Five h after PAM exposure, either PAM $120 \mathrm{~s}$ and $180 \mathrm{~s}$ induced a 3- and 3.7-fold increase, respectively, in $\gamma$-H2AX compared to untreated cells (Figure 6). After $24 \mathrm{~h}$, we recorded a $\gamma$-H2AX increase of 1.8- and 1.4-fold, respectively, compared to untreated cells (Figure 6). Etoposide was used as positive control, showing a 11.3- and 1.5-fold increase after 5 and $24 \mathrm{~h}$, respectively.

Since CAP induced genotoxicity, we analysed whether DNA damage was retained in DNA sequence and expressed as mutations (i.e. irreversible DNA damage). To this end, we performed the micronucleus test on TK6, which represent the cells recommended by the OECD guidelines for performing micronucleus test. [32] PAM $120 \mathrm{~s}$ significantly increased the percentage of $\mathrm{MN}$ of about 3 times with respect to the frequency of untreated cultures. For the positive controls MMC and VINB we recorded an increase in MN percentage of about 4 times compared to untreated cells.

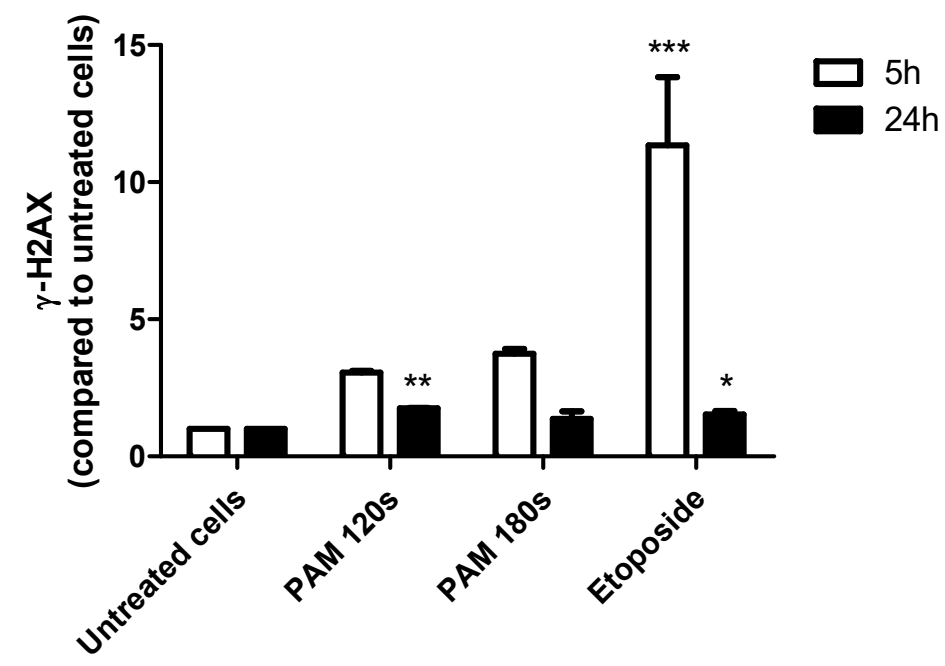


Figure 6. Relative expression of phosphorylated H2AX ( $\gamma$-H2AX) in Jurkat cells 5 or $24 \mathrm{~h}$ after PAM exposure. Etoposide was used as positive control. Results are the mean of three independent experiments. ${ }^{*} \mathrm{p}<0.05 ; * * \mathrm{p}<0.01 ; * * * \mathrm{p}<0.001$ versus untreated cells.

\subsection{PAM induces cell death in Jurkat cells cultured in hypoxic conditions}

Hypoxia is often responsible for the acquisition of chemoresistance [36]. Thus, to better define the pharmacological potential of PAM, we analysed its cytotoxic effects in hypoxic conditions. We observed an increase in apoptotic events, more than necrotic ones, compared to cells cultured in normoxic conditions (Figure 7). The highest percentage of apoptotic events in hypoxia was recorded $48 \mathrm{~h}$ after PAM exposure for $180 \mathrm{~s}$, which resulted about 2-fold higher than untreated cultures. This increase was negligible compared to the apoptosis recorded in normoxic condition, which resulted about 8-fold at the same treatment condition (Figure 7b). Besides, the necrotic events recorded in hypoxic conditions were significantly lower than those observed in normoxia, especially $24 \mathrm{~h}$ after treatment. For example, after PAM exposure for $180 \mathrm{~s}$ we recorded a 16-fold increase in necrotic events in normoxia and a 3-fold increase in hypoxia compared to untreated cells (Figure 7c).

(a)

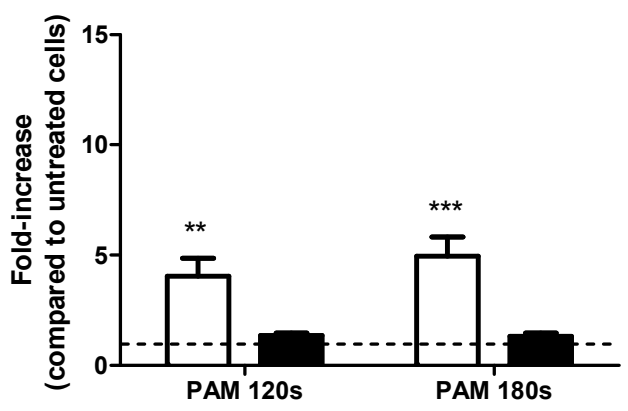

(c)
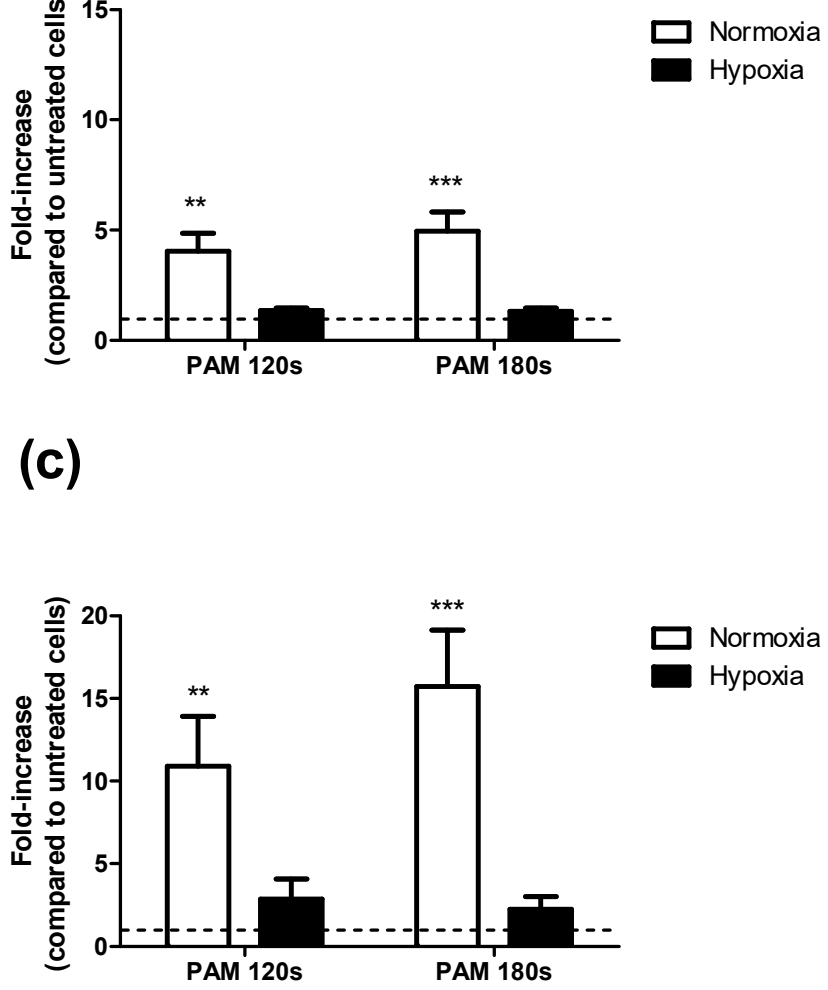

(b)

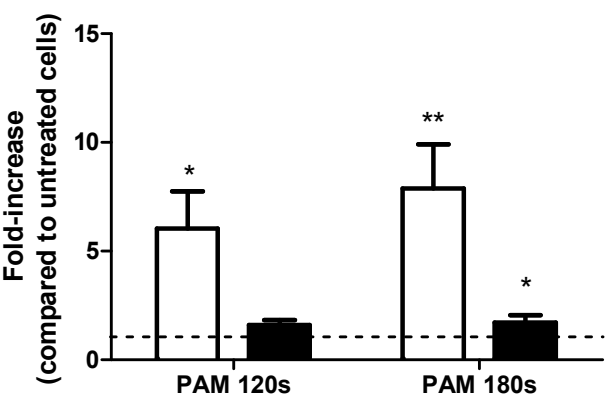

(d)

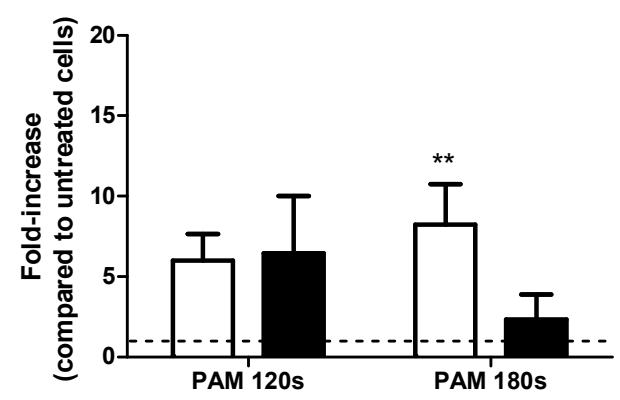

Figure 7. Fold-increase of apoptotic (a,b) or necrotic (c,d) events in Jurkat cells $24(\mathrm{a}, \mathrm{c})$ and $48 \mathrm{~h}$ $(b, d)$ after PAM exposure in normoxic or hypoxic culture conditions. Results are the mean of at 
least three independent experiments. ${ }^{*} \mathrm{p}<0.05 ; * *_{\mathrm{p}}<0.01 ; * * \mathrm{p}<0.001$ versus untreated cells (dashed line).

To understand the mechanisms involved in the different cytotoxic profile of PAM in normoxia versus hypoxia, we measured hydrogen peroxide and nitrites produced in PAM both in normoxic and hypoxic conditions. The concentration of peroxides in hypoxia was lower and nitrites concentration higher than in normoxia in almost all the conditions (Figure 8). The highest difference in peroxides concentration was recorded at PAM $180 \mathrm{~s}$, with $58.8 \mu \mathrm{M}$ in normoxia compared to $33.9 \mu \mathrm{M}$ in hypoxia. The concentrations of nitrites reached the highest difference at PAM 180 s, with $79.9 \mu \mathrm{M}$ in normoxia compared to $126.6 \mu \mathrm{M}$ in hypoxia (Figure 8). On the basis of our results, we can conclude that peroxides produced by plasma treatment in normoxic condition are higher than the ones produce in hypoxic condition, whereas nitrites concentrations resulted higher in hypoxic conditions than in normoxic one.
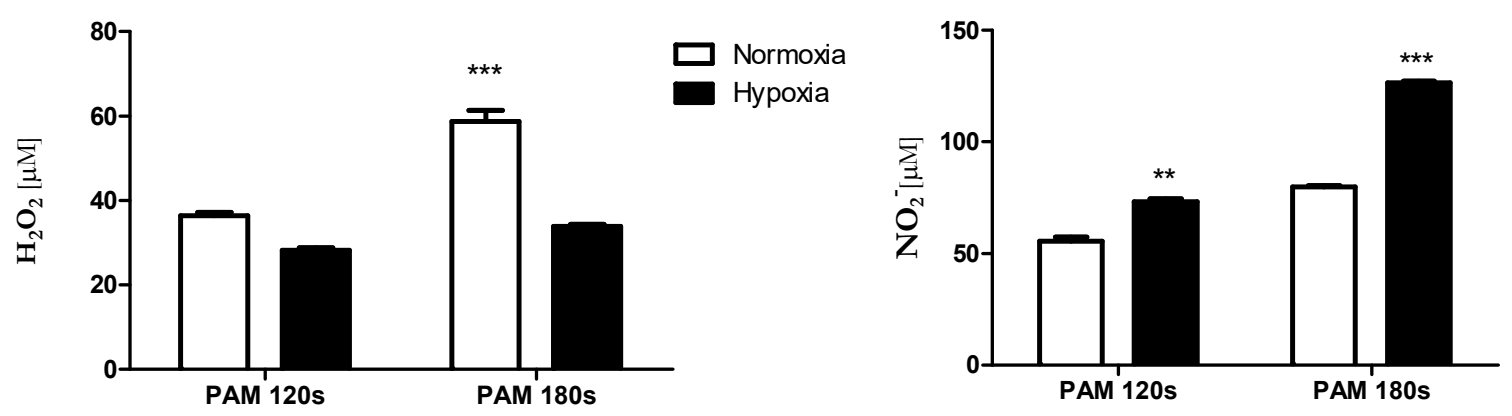

Figure 8. Concentrations of hydrogen peroxide and nitrites in PAM in normoxic and hypoxic conditions. The data are the mean of three different experiments. ${ }^{* *} \mathrm{p}<0.01 ;{ }^{* *} \mathrm{p}$ $<0.001$ normoxia versus hypoxia.

\subsection{The cytotoxicity of PAM is partially selective for tumour cells}

To preliminary assess the selectivity of PAM for cancer cells, normal lymphocytes were treated with PAM. After $24 \mathrm{~h}$ from PAM treatment, we observed a cytotoxic activity of PAM on normal cells. However, it resulted lower than that recorded on leukemic cells (Figure 9). The most significant difference between malignant and normal cells was observed at PAM $180 \mathrm{~s}$, with 77.4\% viability of T-lymphocytes compared to $53.6 \%$ of Jurkat cells (Figure 9). Similar results were obtained after $48 \mathrm{~h}$ from PAM exposure (data not shown). 


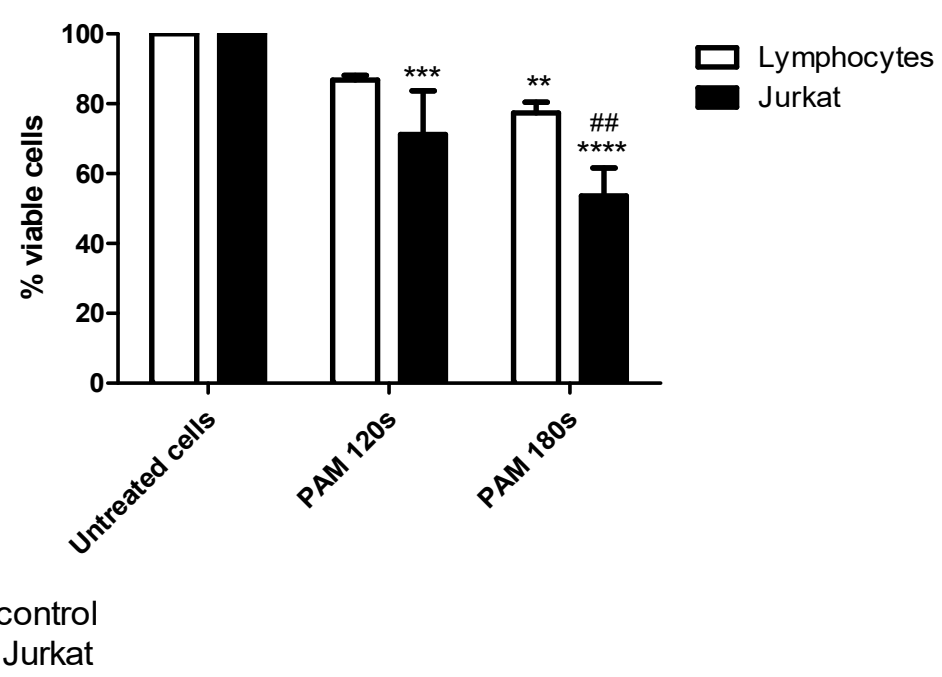

Figure 9. Viability of lymphocytes and Jurkat cells $24 \mathrm{~h}$ after PAM treatment. Results are the mean of two independent experiments. ${ }^{* *} \mathrm{p}<0.01 ; * * * \mathrm{p}<0.001$; **** $\mathrm{p}<0.0001$ versus untreated cells; \#\# $\mathrm{p}<0.01$ versus Jurkat cells.

\section{Discussion}

We investigated PAM antileukemic potential on T-leukemia cells. Usually, cells and tissues are directly exposed to CAP treatment, but in the last years plasma activated liquids, such as PAM, were shown to be equally active in killing cancer cells.[18,37-39] This evidence also emerged from our previous publication with a nanopulsed DBD source in a lymphoma cell line.[40] In the present study, the analysis of cell viability after PAM exposure clearly showed a significant cytotoxic effect at all tested conditions. The hypothesis behind the ability of PAM to trigger cytotoxic effects in tumour models not directly exposed to CAP belongs to the RONS generated in liquid environment, that are involved in a bystander effect-like process.[41] The bystander effect was firstly described for radiations, where cells not directly irradiated showed stress signal factors similar to the irradiated ones. This phenomenon was then described for photodynamic therapy, heat, and chemotherapy agents.[42] The signals responsible for the bystander effects can be either small molecules transported to adjacent non-targeted cells via gap-junction intercellular communication, or secreted factors that can reach remote, non-targeted cells by diffusion or through circulation. Reactive species and alteration of cells redox status are considered among the main responsible factors underpinning bystander effect.[43] Besides, secondary CAP-generated and most long-lived RONS in liquid phase (peroxides and nitrites) are considered the predominant players of PAM-induced biological effects.[44] Moreover, Kurake et al. [45] and Girard et al. [46] have pointed out that the synergistic interaction between $\mathrm{H}_{2} \mathrm{O}_{2}$ and nitrite is essential for PAM action.

Deepening the mechanisms of cell death induced by the DBD jet source, object of this study, we observed a significant induction of apoptotic events 24 and $48 \mathrm{~h}$ after PAM exposure. Also, if PAM treatment only lasted $1 \mathrm{~h}$, its effect perdured for several hours: it is interesting to record up to $48 \mathrm{~h}$ its pro-apoptotic activity, even higher than recorded necrotic events. This is not the first time that apoptosis is observed several hours after CAP exposure.[47,48] The cytotoxic effect of CAP depends on the exposure time, the progressive increase in the reactive species formation and the initiation of 
an intracellular signalling cascade that leads to programmed cell death.[49] Furthermore, the selfperpetuation of apoptosis was recently imputed to the formation of secondary extracellular singlet oxygen generated by CAP treatment, that leads to apoptosis via inactivation of local catalase.[41] Tumour cells acquire protective membrane-associated catalase and SOD to cope with intercellular RONS-dependent apoptosis. Thus, inactivation of membrane-associated catalase by singlet oxygen could perpetuate apoptosis in tumour cells.[50] The clarification of these aspects for PAM-mediated apoptosis induction requires further experimentation.

Different groups recently reviewed the interaction between CAP and liquids, suggesting peroxides and nitrites as the main molecules exerting an anticancer effect.[10] These reactive species, as previously mentioned, are considered the main responsible for the activation of signalling cascades that mediate CAP-induced pro-apoptotic effects.[51] In this context, Fenton reactions, that in presence of an iron atom catalyse the formation of hydroxyl radical, might be key reactions in cell-based peroxides generation.[52] Our results clearly confirmed the important role of RONS in PAM, demonstrating that the scavenger activity of O-phe, that specifically blocks Fenton reaction, or NAC, that increases the antioxidant defence of the cells, inhibits PAM cytotoxicity. More protracted is the cell exposure to scavenger, less effective is PAM in inducing cancer cell death, as we demonstrated with longer exposure to NAC. However, in our conditions, treatment with NAC did not totally abolish the cytotoxic effect of PAM, thus suggesting a synergistic role of RNS and peroxides [46]. Furthermore, we demonstrated that PAM induces a depletion of GSH. The GSH reduction affects the antioxidant capacity of the coupled glutathione peroxidase-glutathione Stransferases system and could therefore sensitize target cells to oxidative stress.[53]

We also observed that the pro-apoptotic activity of PAM depends on the activation of the intrinsic pathway, as demonstrated by the significant increase in cells with decreased mitochondrial potential after PAM treatment. During the effector phase of mitochondria-dependent apoptosis, the transmembrane potential of mitochondria collapses, indicating the opening of the transition pores. Once mitochondrial membrane integrity is compromised, different signals converge for the activation of apoptosis, including ATP decay, uncoupled oxidative phosphorylation, release of apoptogenic factors, such as cytochrome c, and alteration of cellular redox pathway [54]. Recently, Ahn et al. reported the ability of CAP to induce apoptosis through the activation of the intrinsic pathway, prompted by free radical generation,[55] thus further supporting our results that scavengers must alleviate CAP pro-apoptotic activity.

Together with the induction of apoptosis, we demonstrated that PAM treatments alter cell-cycle residence, inducing a block in $\mathrm{S}$ and $\mathrm{G} 2 / \mathrm{M}$ phases. Cell-cycle block prevents aged or abnormal cells from proliferation. ROS generated by CAP are considered among the main responsible for DNA damage induction, which leads to cell-cycle arrest and then apoptosis.[56] Volotskova and colleagues found that CAP delayed progression of skin cancer cells by blocking them at the G2/M checkpoint. This delay correlated with the increase in H2AX phosphorylation, a marker of DNA double-strand break.[57] Notably, apoptosis can be activated as secondary response to DNA damage after DNA repair failed.[58] Our results showed that apoptosis is not completely efficient in the elimination of damaged cells, as demonstrated by the increase in H2AX phosphorylation and the MN frequency after PAM treatment. Indeed, many species produced by CAP treatment of liquids are likely to cause DNA damage [among others hydrogen peroxide $\left(\mathrm{H}_{2} \mathrm{O}_{2}\right)$ ].[59] Nevertheless, conflicting results are available on CAP genotoxicity and mutagenicity. Wende and colleagues demonstrated that CAP treatment up to $180 \mathrm{~s}$ with an argon plasma jet did not increase genotoxicity in fibroblasts and keratinocytes.[60] On the other hand, Hong and collaborators showed a significant increase in the occurrence of chromosomal damage after exposure of B lymphoblastoid WIL2-NS 
cells to an argon plasma-jet-treated media [61]. Thus, it is necessary to point out that every CAP source induces different plasma compositions, and thus induces different chemistry in liquid phase, that therefore needs to be assessed for efficacy and safety. Furthermore, the treatment conditions, i.e. time of exposure to CAP, strongly influence CAP toxicity [62].

Although in a lesser extent compared to normoxia, PAM showed pro-apoptotic activity also in hypoxia. To the best of our knowledge, this is the first time that the biological effect of PAM has been investigated in hypoxic conditions. The reason at the basis of this different cytotoxic activity may lie in the different concentration of peroxides and nitrites produced in activated medium in normoxia versus hypoxia. [22] The lower concentration of hydrogen peroxide produced in hypoxia compared to normoxia lies in the low concentration of oxygen in atmosphere. Indeed one of the most important precursor of hydrogen peroxide is hydroxyl radical produced in gas phase [63], whose production is mainly related to oxygen molecules and $\mathrm{HO}_{2}$. [64] Focusing on nitrites, Tresp et al. [65] demonstrated that plasma jet generated in a nitrogen-rich atmosphere induces a higher concentration of nitrites in RPMI compared to a jet generated in synthetic air atmosphere. This can be related to the higher concentration of nitrogen, precursor of NO in gas phase, main responsible of nitrites production in liquid.

Tumour cells cultured in hypoxic conditions can respond differently to pharmacological treatment and develop chemoresistance.[36] This is reasonably due to changes in cell metabolism and microenvironment caused by reduced oxygen tension.[66] It was recently proposed that CAP can induce apoptosis inside a tumour by the delivery of peroxides and nitrites coupled with aqueous oxygen, this latter responsible also for the increase in oxygen tension in the hypoxic tissue. [67,68]. Accordingly, in vivo data showed that a plasma jet source increased both blood flow and tissue oxygen partial pressure. [69]

To further assess the potential of CAP as anticancer strategy, we investigated PAM selectivity for cancer cells. In particular, we explored the cytotoxic effects of PAM on normal lymphocytes from healthy donors. Our results show a partial selectivity of PAM towards malignant cells. Previous studies demonstrated the non-aggressive nature of CAP on primary or stem cells [70] and its more pronounced or selective cytotoxic activity versus malignant cells in several tissues, such as lung,[71] liver,[72] and melanocytes.[73] Besides, Bundscherer and colleagues showed that i) freshly isolated blood cells were more susceptible to CAP treatment than cell lines; ii) CAP cytotoxic effects on normal lymphocytes depended on cell type (e.g. memory lymphocytes more sensitive compared to monocytes), [74] envisioning a degree of selectivity, rather than universal selectivity of CAP. [12] The theory behind CAP partial selectivity is that tumour cells are usually characterized by an increased basal oxidative stress, making them more vulnerable to a further increase in intracellular ROS levels compared to normal cells. [75] Thus, the increase in oxidative stress induced by CAP will preferentially target tumour cells. Furthermore, cancer cells express more aquaporins on their cytoplasmic membranes, which may cause the $\mathrm{H}_{2} \mathrm{O}_{2}$ uptake in cancer cells to be faster than in normal cells. As a result, CAP treatment could kill cancer cells more easily than normal cells.[76] The increased uptake of RONS in cancer cells compared to normal ones was recently assessed also by the different composition of the cholesterol fraction of cell membrane. The lowest content of cholesterol in the phospholipid bilayers of cancer cells could allow a highest permeability of cancer cells to those reactive species.[77]

Ex vivo samples are good surrogates to predict the pharmacological response of patients. Cell lines differ from primary cells, taken directly from living tissue, in term of growth kinetics and pharmacological determinants (e.g. sex, age, presence of mutations, etc...) .[78] We obtained preliminary results on blasts from patients with acute myeloid leukemia (see Supplementary 
Materials, Supplementary Table 1, Figure S1), where PAM induced a milder cytotoxic effect compared to T-leukemia Jurkat cells. A different cytotoxic effect of CAP in primary cells compared to cell lines was observed, for example, for prostate cancer. Hirst and colleagues recorded necrosis and autophagy in primary cells, whereas they observed apoptosis together with necrosis in prostate cell lines. These results further underline the need of studies in primary cultures to better predict the clinical potential of CAP and PAM.[79] In our experimental system, the more pronounced activity on blast samples was observed on cells from patients negative for mutations on the tyrosine-kinase domain (TKD) of the FMS-like tyrosine-kinase 3 (FLT3) (Figure S1). Internal tandem duplications (ITD) and FLT3 mutations can be found in up to one third of patients with AML.[80] The presence of FLT3/IDT mutations is often associated with a high relapse rate and a short relapsed-free and overall survival after chemotherapy and transplant.[81] PAM cytotoxic activity is negligible in blasts from FLT3 positive/ITD patients, except for blasts from one relapsing patient (Figure S1).

However, to make these data consistent it will be necessary to expand the number of samples and to test the in vitro response of blasts to conventional chemotherapeutic drugs (i.e. cytarabine, idarubicin), especially for relapsing and refractory patients.

Of note, one of the main limits of a pro-oxidant anticancer therapy, such as CAP treatment, could be represented by the occurrence of resistance.[82] The presence of nitrogen reactive species and the possibility to control and diversify CAP-produced reactive species could represent an important strategy to overcome chemoresistance. More, other molecules can contribute to enhance the cytotoxic mechanism evoked by CAP. Recent studies actually showed how the complexity of CAP could counteract the resistance in oxidation-insensitive types of cancer. Bekeschus and colleagues demonstrated that leukemia THP-1 cells, insensitive to CAP-induced cell death mediated by peroxides stress, become sensitive to CAP treatment when hypochlorous acid is produced tailoring CAP chemistry, using a helium/oxygen radio frequency driven atmospheric plasma jet.[83]

\section{Conclusions}

Taken together, our results provide a deeper understanding on the cellular and molecular impact of PAM in in vitro leukemia cells, highlighting its partial selectivity towards malignant cells and its cytotoxic activity in model of chemoresistance, such as cell cultured in hypoxia. Further investigation in the mechanisms triggering CAP biological effects, the role of catalase or hypochlorous acid in PAM-induced leukemic cell death will certainly help in the prediction of CAP clinical potential. The knowledge obtained on the anticancer mechanisms of CAP could allow to predict a synergistic effect of CAP with well-known modulators of RONS signalling and traditional chemotherapy. Those associations could decrease the time of CAP exposure necessary to induce optimal anticancer effects, potentially improving its toxicological profile and increasing its efficacy.

\section{Funding statement}

This work was supported by National SIR Grant [RBSI14DBMB] of the Italian Ministry of Education, Universities and Research, MIUR.

\section{Data availability}

All data reported have been obtained from experiments carried out in the authors' laboratory.

\section{Conflicts of interest}


The authors declare no conflict of interest.

\section{Acknowledgments}

For critical suggestions and discussion, we thank Prof. Georg Bauer, Institute of Virology, University Medical Centre Freiburg, Germany. We thank Alina Bisag for the support in the realization of Fig.1

\section{References}

1. Fridman, G.; Friedman, G.; Gutsol, A.; Shekhter, A.B.; Vasilets, V.N.; Fridman, A. Applied plasma medicine. Plasma Processes and Polymers 2008, 5, 503-533.

2. Fridman, A.A.; Friedman, G.G. Plasma medicine; John Wiley \& Sons Chichester, UK:: 2013.

3. Yousfi, M.; Merbahi, N.; Pathak, A.; Eichwald, O. Low-temperature plasmas at atmospheric pressure: toward new pharmaceutical treatments in medicine. Fundamental \& clinical pharmacology 2014, 28, 123-135.

4. Yan, D.; Sherman, J.H.; Keidar, M. Cold atmospheric plasma, a novel promising anti-cancer treatment modality. Oncotarget 2017, 8, 15977.

5. Hirst, A.M.; Frame, F.M.; Arya, M.; Maitland, N.J.; O'Connell, D. Low temperature plasmas as emerging cancer therapeutics: the state of play and thoughts for the future. Tumor Biology 2016, 37, 7021-7031.

6. Graves, D.B. Reactive species from cold atmospheric plasma: implications for cancer therapy. Plasma Processes and Polymers 2014, 11, 1120-1127.

7. Laroussi, M. From killing bacteria to destroying cancer cells: 20 years of plasma medicine. Plasma Processes and Polymers 2014, 11, 1138-1141.

8. Ratovitski, E.A.; Cheng, X.; Yan, D.; Sherman, J.H.; Canady, J.; Trink, B.; Keidar, M. Anti-cancer therapies of 21st century: novel approach to treat human cancers using cold atmospheric plasma. Plasma Processes and Polymers 2014, 11, 1128-1137.

9. Schlegel, J.; Köritzer, J.; Boxhammer, V. Plasma in cancer treatment. Clinical Plasma Medicine 2013, 1, 2-7, doi:10.1016/j.cpme.2013.08.001.

10. Tanaka, H.; Mizuno, M.; Ishikawa, K.; Toyokuni, S.; Kajiyama, H.; Kikkawa, F.; Hori, M. Molecular mechanisms of non-thermal plasma-induced effects in cancer cells. Biological chemistry 2018.

11. Miller, V.; Lin, A.; Fridman, G.; Dobrynin, D.; Fridman, A. Plasma Stimulation of Migration of Macrophages. 2014, 11, 1193-1197, doi:10.1002/ppap.201400168.

12. Bekeschus, S.; Favia, P.; Robert, E.; Von Woedtke, T. White paper on plasma for medicine and hygiene: Future in plasma health sciences. Plasma Processes and Polymers 2019, 16, 1800033, doi:10.1002/ppap.201800033.

13. Kumara, R.; Susara, M.H.; Piao, M.J.; Kang, K.A.; Ryu, Y.S.; Park, J.E.; Shilnikova, K.; Jo, J.O.; Mok, Y.S.; Shin, J.H. Non-thermal gas plasma-induced endoplasmic reticulum stress mediates apoptosis in human colon cancer cells. Oncology reports 2016, 36, 2268-2274.

14. Furuta, T.; Shi, L.; Toyokuni, S. Non-thermal plasma as a simple ferroptosis inducer in cancer cells: A possible role of ferritin. Pathology international 2018.

15. Lin, A.; Xiang, B.; Merlino, D.J.; Baybutt, T.R.; Sahu, J.; Fridman, A.; Snook, A.E.; Miller, V. Nonthermal plasma induces immunogenic cell death in vivo in murine CT26 colorectal tumors.

Oncolmmunology 2018. 
16. GARG, A.; Dudek-Peric, A.M.; Romano, E.; Agostinis, P. Immunogenic cell death. The International journal of developmental biology 2015, 59, 131-140.

17. Tanaka, M.; Mizuno, M.; Ishikawa, K.; Nakamura, K.; Kajiyama, H.; Kano, H.; Kikkawa, F.; Hori, M. Plasma Medicine 2011 1, 265-277.

18. Kaushik, N.K.; Ghimire, B.; Li, Y.; Adhikari, M.; Veerana, M.; Kaushik, N.; Jha, N.; Adhikari, B.; Lee, S.J.; Masur, K., et al. Biological and medical applications of plasma-activated media, water and solutions. Biol Chem 2018, 400, 39-62, doi:10.1515/hsz-2018-0226.

19. Metelmann, H.-R.; Nedrelow, D.S.; Seebauer, C.; Schuster, M.; von Woedtke, T.; Weltmann, K.-D.; Kindler, S.; Metelmann, P.H.; Finkelstein, S.E.; Von Hoff, D.D. Head and neck cancer treatment and physical plasma. Clinical Plasma Medicine 2015, 3, 17-23.

20. Dubuc, A.; Monsarrat, P.; Virard, F.; Merbahi, N.; Sarrette, J.-P.; Laurencin-Dalicieux, S.; Cousty, S. Use of cold-atmospheric plasma in oncology: a concise systematic review. Therapeutic advances in medical oncology 2018, 10, 1758835918786475.

21. Bosanquet, A.G.; Bell, P.B. Ex vivo therapeutic index by drug sensitivity assay using fresh human normal and tumor cells. J Exp Ther Oncol 2004, 4, 145-154.

22. Busco, G.; Fasani, F.; Dozias, S.; Ridou, L.; Douat, C.; Pouvesle, J.-M.; Robert, E.; Grillon, C. Changes in Oxygen Level Upon Cold Plasma Treatments: Consequences for RONS Production. IEEE Transactions on Radiation and Plasma Medical Sciences 2018, 2, 147-152, doi:10.1109/trpms.2017.2775705.

23. Nombela-Arrieta, C.; Pivarnik, G.; Winkel, B.; Canty, K.J.; Harley, B.; Mahoney, J.E.; Park, S.-Y.; Lu, J.; Protopopov, A.; Silberstein, L.E. Quantitative imaging of haematopoietic stem and progenitor cell localization and hypoxic status in the bone marrow microenvironment. Nature Cell Biology 2013, 15, 533-543, doi:10.1038/ncb2730.

24. Parmar, K.; Mauch, P.; Vergilio, J.-A.; Sackstein, R.; Down, J.D. Distribution of hematopoietic stem cells in the bone marrow according to regional hypoxia. Proceedings of the National Academy of Sciences 2007, 104, 5431-5436, doi:10.1073/pnas.0701152104.

25. Mamede, A.C.; Abrantes, A.M.; Pedrosa, L.; Casalta-Lopes, J.E.; Pires, A.S.; Teixo, R.J.; Gon; \#xe7; alves, A.C.; Sarmento-Ribeiro, A.B., et al. Beyond the Limits of Oxygen: Effects of Hypoxia in a Hormone-Independent Prostate Cancer Cell Line. ISRN Oncology 2013, 2013, 8 , doi:10.1155/2013/918207.

26. Notte, A.; Ninane, N.; Arnould, T.; Michiels, C. Hypoxia counteracts taxol-induced apoptosis in MDA-MB-231 breast cancer cells: role of autophagy and JNK activation. Cell Death \& Disease 2013, 4, e638-e638, doi:10.1038/cddis.2013.167.

27. Selvendiran, K.; Bratasz, A.; Kuppusamy, M.L.; Tazi, M.F.; Rivera, B.K.; Kuppusamy, P. Hypoxia induces chemoresistance in ovarian cancer cells by activation of signal transducer and activator of transcription 3. International Journal of Cancer 2009, 125, 2198-2204, doi:10.1002/ijc.24601.

28. Jensen, P. Ф.; Mortensen, B.T.; Hodgkiss, R.J.; Iversen, P.O.; Christensen, I.J.; Helledie, N.; Larsen, J.K. Increased cellular hypoxia and reduced proliferation of both normal and leukaemic cells during progression of acute myeloid leukaemia in rats. Cell Proliferation 2000, 33, 381-395, doi:10.1046/j.1365-2184.2000.00183.x.

29. Simoncelli, E.; Barbieri, D.; Laurita, R.; Liguori, A.; Stancampiano, A.; Viola, L.; Tonini, R.; Gherardi, M.; Colombo, V. Preliminary investigation of the antibacterial efficacy of a handheld Plasma Gun source for endodontic procedures. Clinical Plasma Medicine 2015, 3, 77-86.

30. De Nicola, M.; Ghibelli, L. Glutathione depletion in survival and apoptotic pathways. Frontiers in Pharmacology 2014, 5, doi:10.3389/fphar.2014.00267.

31. Bradford, M.M. A rapid and sensitive method for the quantitation of microgram quantities of protein utilizing the principle of protein-dye binding. Analytical biochemistry 1976, 72, 248-254.

32. OECD. Test No. 487: In Vitro Mammalian Cell Micronucleus Test; 2016; doi:https://doi.org/10.1787/9789264224438-en.

33. Avlasevich, S.; Bryce, S.; De Boeck, M.; Elhajouji, A.; Van Goethem, F.; Lynch, A.; Nicolette, J.; Shi, J.; Dertinger, $\mathrm{S}$. Flow cytometric analysis of micronuclei in mammalian cell cultures: past, present and future. Mutagenesis 2011, 26, 147-152, doi:10.1093/mutage/geq058. 
34. Lenzi, M.; Cocchi, V.; Hrelia, P. Flow cytometry vs optical microscopy in the evaluation of the genotoxic potential of xenobiotic compounds. Cytometry B Clin Cytom 2018, 94, 696-706, doi:10.1002/cyto.b.21546.

35. De Nicola, M.; Ghibelli, L. Glutathione depletion in survival and apoptotic pathways. Front Pharmacol 2014, 5, 267, doi:10.3389/fphar.2014.00267.

36. Rharass, T.; Vigo, J.; Salmon, J.-M.; Ribou, A.-C. New method for the detection of reactive oxygen species in anti-tumoural activity of adriamycin: a comparison between hypoxic and normoxic cells. Free radical research 2008, 42, 124-134.

37. Yan, D.; Talbot, A.; Nourmohammadi, N.; Cheng, X.; Canady, J.; Sherman, J.; Keidar, M. Principles of using cold atmospheric plasma stimulated media for cancer treatment. Scientific reports 2015, 5, 18339.

38. Florian, J.; Merbahi, N.; Yousfi, M. Genotoxic and cytotoxic effects of plasma-activated media on multicellular tumor spheroids. Plasma Medicine 2016, 6.

39. Kumar, N.; Park, J.H.; Jeon, S.N.; Park, B.S.; Choi, E.H.; Attri, P. The action of microsecond-pulsed plasma-activated media on the inactivation of human lung cancer cells. Journal of Physics $D$ : Applied Physics 2016, 49, 115401.

40. Gherardi, M.; Turrini, E.; Laurita, R.; De Gianni, E.; Ferruzzi, L.; Liguori, A.; Stancampiano, A.; Colombo, V.; Fimognari, C. Atmospheric Non-Equilibrium Plasma Promotes Cell Death and CellCycle Arrest in a Lymphoma Cell Line. Plasma Processes and Polymers 2015, 12, 1354-1363.

41. Bauer, G.; Graves, D.B. Mechanisms of Selective Antitumor Action of Cold Atmospheric PlasmaDerived Reactive Oxygen and Nitrogen Species. Plasma Processes and Polymers 2016, 13, 11571178.

42. Verma, N.; Tiku, A.B. Significance and nature of bystander responses induced by various agents. Mutat Res 2017, 773, 104-121, doi:10.1016/j.mrrev.2017.05.003.

43. Klammer, H.; Mladenov, E.; Li, F.; lliakis, G. Bystander effects as manifestation of intercellular communication of DNA damage and of the cellular oxidative status. Cancer Lett 2015, 356, 58-71, doi:10.1016/j.canlet.2013.12.017.

44. Yan, D.; Xu, W.; Yao, X.; Lin, L.; Sherman, J.H.; Keidar, M. The Cell Activation Phenomena in the Cold Atmospheric Plasma Cancer Treatment. Scientific reports 2018, 8, 15418.

45. Kurake, N.; Tanaka, H.; Ishikawa, K.; Kondo, T.; Sekine, M.; Nakamura, K.; Kajiyama, H.; Kikkawa, F.; Mizuno, M.; Hori, M. Cell survival of glioblastoma grown in medium containing hydrogen peroxide and/or nitrite, or in plasma-activated medium. Archives of biochemistry and biophysics 2016, 605, 102-108.

46. Girard, P.-M.; Arbabian, A.; Fleury, M.; Bauville, G.; Puech, V.; Dutreix, M.; Sousa, J.S. Synergistic effect of $\mathrm{H} 2 \mathrm{O} 2$ and NO 2 in cell death induced by cold atmospheric He plasma. Scientific reports 2016, 6, 29098.

47. Fridman, G.; Shereshevsky, A.; Jost, M.M.; Brooks, A.D.; Fridman, A.; Gutsol, A.; Vasilets, V.; Friedman, $G$. Floating electrode dielectric barrier discharge plasma in air promoting apoptotic behavior in melanoma skin cancer cell lines. Plasma Chemistry and Plasma Processing 2007, 27, 163-176.

48. Thiyagarajan, M.; Waldbeser, L.; Whitmill, A. THP-1 leukemia cancer treatment using a portable plasma device. Studies in health technology and informatics 2012, 173, 515-517.

49. Barekzi, N.; Laroussi, M. Dose-dependent killing of leukemia cells by low-temperature plasma. Journal of Physics D: Applied Physics 2012, 45, 422002.

50. Bauer, G. Increasing the endogenous NO level causes catalase inactivation and reactivation of intercellular apoptosis signaling specifically in tumor cells. Redox Biol 2015, 6, 353-371, doi:10.1016/j.redox.2015.07.017.

51. Bruggeman, P.; Kushner, M.J.; Locke, B.R.; Gardeniers, J.G.; Graham, W.; Graves, D.B.; HofmanCaris, R.; Maric, D.; Reid, J.P.; Ceriani, E. Plasma-liquid interactions: a review and roadmap. Plasma sources science and technology 2016, 25, 053002.

52. Adachi, T.; Nonomura, S.; Horiba, M.; Hirayama, T.; Kamiya, T.; Nagasawa, H.; Hara, H. Iron stimulates plasma-activated medium-induced A549 cell injury. Scientific reports 2016, 6, 20928. 
53. Corso, C.R.; Acco, A. Glutathione system in animal model of solid tumors: From regulation to therapeutic target. Critical reviews in oncology/hematology 2018.

54. Moncada, S. Mitochondria as pharmacological targets. British journal of pharmacology 2010, 160, 217-219.

55. Ahn, H.J.; Kim, K.I.; Kim, G.; Moon, E.; Yang, S.S.; Lee, J.-S. Atmospheric-pressure plasma jet induces apoptosis involving mitochondria via generation of free radicals. PloS one 2011, 6, e28154.

56. Vandamme, M.; Robert, E.; Lerondel, S.; Sarron, V.; Ries, D.; Dozias, S.; Sobilo, J.; Gosset, D.; Kieda, C.; Legrain, B. ROS implication in a new antitumor strategy based on non-thermal plasma. International journal of cancer 2012, 130, 2185-2194.

57. Volotskova, O.; Hawley, T.S.; Stepp, M.A.; Keidar, M. Targeting the cancer cell cycle by cold atmospheric plasma. Scientific reports 2012, 2, 636.

58. Wang, J. DNA damage and apoptosis. Nature Publishing Group: 2001.

59. Arjunan, K.P.; Sharma, V.K.; Ptasinska, S. Effects of atmospheric pressure plasmas on isolated and cellular DNA-a review. Int J Mol Sci 2015, 16, 2971-3016, doi:10.3390/ijms16022971.

60. Wende, K.; Bekeschus, S.; Schmidt, A.; Jatsch, L.; Hasse, S.; Weltmann, K.; Masur, K.; von Woedtke, $\mathrm{T}$. Risk assessment of a cold argon plasma jet in respect to its mutagenicity. Mutation Research/Genetic Toxicology and Environmental Mutagenesis 2016, 798, 48-54.

61. Hong, S.-H.; Szili, E.J.; Fenech, M.; Gaur, N.; Short, R.D. Genotoxicity and cytotoxicity of the plasma jet-treated medium on lymphoblastoid WIL2-NS cell line using the cytokinesis block micronucleus cytome assay. Scientific reports 2017, 7, 3854.

62. Turrini, E.; Laurita, R.; Stancampiano, A.; Catanzaro, E.; Calcabrini, C.; Maffei, F.; Gherardi, M.; Colombo, V.; Fimognari, C. Cold atmospheric plasma induces apoptosis and oxidative stress pathway regulation in T-lymphoblastoid leukemia cells. Oxidative medicine and cellular longevity 2017, 2017.

63. Gorbanev, Y.; O'Connell, D.; Chechik, V. Non-Thermal Plasma in Contact with Water: The Origin of Species. Chemistry-A European Journal 2016, 22, 3496-3505.

64. Van Gaens, W.; Bogaerts, A. Reaction pathways of biomedically active species in an Ar plasma jet. Plasma Sources Science and Technology 2014, 23, 035015.

65. Tresp, H.; Hammer, M.U.; Weltmann, K.-D.; Reuter, S. Effects of atmosphere composition and liquid type on plasma-generated reactive species in biologically relevant solutions. Plasma Medicine 2013, 3.

66. Shannon, A.M.; Bouchier-Hayes, D.J.; Condron, C.M.; Toomey, D. Tumour hypoxia, chemotherapeutic resistance and hypoxia-related therapies. Cancer treatment reviews 2003, 29, 297-307.

67. Szili, E.J.; Oh, J.-S.; Fukuhara, H.; Bhatia, R.; Gaur, N.; Nguyen, C.K.; Hong, S.-H.; Ito, S.; Ogawa, K.; Kawada, C. Modelling the helium plasma jet delivery of reactive species into a 3D cancer tumour. Plasma Sources Science and Technology 2017, 27, 014001.

68. Lu, X.; Keidar, M.; Laroussi, M.; Choi, E.; Szili, E.J.; Ostrikov, K. Transcutaneous plasma stress: From soft-matter models to living tissues. Materials Science and Engineering: R: Reports 2019, 138, 3659, doi:10.1016/j.mser.2019.04.002.

69. Collet, G.; Robert, E.; Lenoir, A.; Vandamme, M.; Darny, T.; Dozias, S.; Kieda, C.; Pouvesle, J.M. Plasma jet-induced tissue oxygenation: potentialities for new therapeutic strategies. 2014, 23, 012005, doi:10.1088/0963-0252/23/1/012005.

70. Ma, Y.; Ha, C.S.; Hwang, S.W.; Lee, H.J.; Kim, G.C.; Lee, K.-W.; Song, K. Non-thermal atmospheric pressure plasma preferentially induces apoptosis in p53-mutated cancer cells by activating ROS stress-response pathways. PloS one 2014, 9, e91947.

71. Panngom, K.; Baik, K.; Nam, M.; Han, J.; Rhim, H.; Choi, E. Preferential killing of human lung cancer cell lines with mitochondrial dysfunction by nonthermal dielectric barrier discharge plasma. Cell death \& disease 2013, 4, e642.

72. Gweon, B.; Kim, M.; Bee Kim, D.; Kim, D.; Kim, H.; Jung, H.; H. Shin, J.; Choe, W. Differential responses of human liver cancer and normal cells to atmospheric pressure plasma. Applied Physics Letters 2011, 99, 063701. 
73. Arndt, S.; Wacker, E.; Li, Y.F.; Shimizu, T.; Thomas, H.M.; Morfill, G.E.; Karrer, S.; Zimmermann, J.L.; Bosserhoff, A.K. Cold atmospheric plasma, a new strategy to induce senescence in melanoma cells. Experimental dermatology 2013, 22, 284-289.

74. Bundscherer, L.; Bekeschus, S.; Tresp, H.; Hasse, S.; Reuter, S.; Weltmann, K.-D.; Lindequist, U.; Masur, K. Viability of Human Blood Leukocytes Compared with Their Respective Cell Lines after Plasma Treatment. 2013, 3, 71-80, doi:10.1615/plasmamed.2013008538.

75. Weinberg, F.; Chandel, N.S. Reactive oxygen species-dependent signaling regulates cancer. Cellular and molecular life sciences 2009, 66, 3663.

76. Yan, D.; Talbot, A.; Nourmohammadi, N.; Sherman, J.H.; Cheng, X.; Keidar, M. Toward understanding the selective anticancer capacity of cold atmospheric plasma-A model based on aquaporins. Biointerphases 2015, 10, 040801.

77. Van der Paal, J.; Verheyen, C.; Neyts, E.C.; Bogaerts, A. Hampering effect of cholesterol on the permeation of reactive oxygen species through phospholipids bilayer: possible explanation for plasma cancer selectivity. Scientific reports 2017, 7, 39526.

78. Bosanquet, A.G.; Burlton, A.R.; Bell, P.B. Parameters affecting the ex vivo cytotoxic drug sensitivity of human hematopoietic cells. Journal of Experimental Therapeutics and Oncology 2002, 2, 53-63.

79. Hirst, A.; Simms, M.; Mann, V.; Maitland, N.; O'connell, D.; Frame, F. Low-temperature plasma treatment induces DNA damage leading to necrotic cell death in primary prostate epithelial cells. British journal of cancer 2015, 112, 1536.

80. Leick, M.B.; Levis, M.J. The Future of Targeting FLT3 Activation in AML. Curr Hematol Malig Rep 2017, 12, 153-167, doi:10.1007/s11899-017-0381-2.

81. Larrosa-Garcia, M.; Baer, M.R. FLT3 Inhibitors in Acute Myeloid Leukemia: Current Status and Future Directions. Mol Cancer Ther 2017, 16, 991-1001, doi:10.1158/1535-7163.mct-16-0876.

82. Landriscina, M.; Maddalena, F.; Laudiero, G.; Esposito, F. Adaptation to oxidative stress, chemoresistance, and cell survival. Antioxidants \& redox signaling 2009, 11, 2701-2716.

83. Bekeschus, S.; Wende, K.; Hefny, M.M.; Rödder, K.; Jablonowski, H.; Schmidt, A.; Von Woedtke, T.; Weltmann, K.-D.; Benedikt, J. Oxygen atoms are critical in rendering THP-1 leukaemia cells susceptible to cold physical plasma-induced apoptosis. Scientific reports 2017, 7, 2791.

\section{Graphical Abstract}

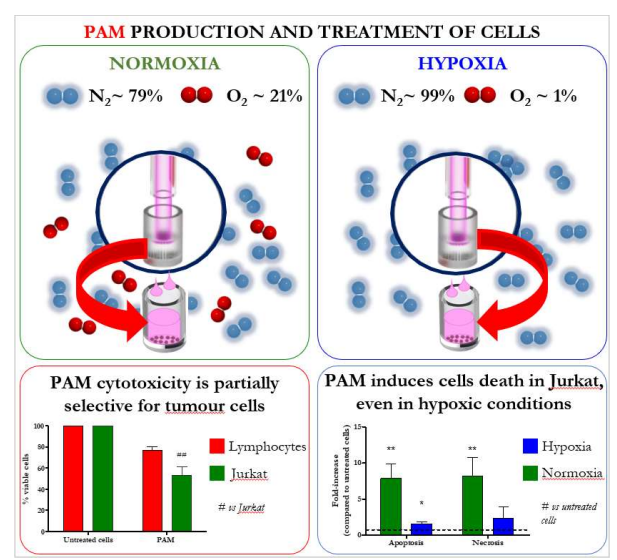

A dielectric barrier discharge plasma jet is used for the production of plasma activated medium (PAM). On T-lymphoblastic cell line, PAM induces apoptosis through the activation of the intrinsic pathway and inhibited cell-cycle progression. PAM shows cytotoxic effects even on 
leukemia cells cultivated in hypoxia, which plays a critical role in promoting chemoresistance.

PAM is also tested on normal lymphocytes, showing its partial selectivity.

\section{Supporting Information}

Preliminary results on PAM cytotoxic effects on blasts from eight patients with acute myeloid leukemia classified as FLT3 positive or negative. Table S1: Clinical features of patients. Figure S1: Percentage of viable blasts $24 \mathrm{~h}$ after PAM treatment. 